\title{
Los cazadores recolectores "perdidos del formativo" en la interacción Andes y Amazonia del septentrión ecuatoriano (1400 - 400 a.C.)
}

Sthefano Serrano*

El presente artículo forma parte de una inVestigación llevada a Cabo entre las regiones ANDES Y Amazonía, específicamente en la zona de influencia de los volcanes Antisana y Cayambe (Serrano, 2017 ). BAJO LA PROPUESTA dE UN MODELO DE INTERCAMBIO, INFERIDO A TRAVÉS DE LA ETNOARQUEOLOGÍA (INTERCAMBIO RECÍPROCO ENTRE UNIDADES DOMÉSTICAS) Y EN BASE A LOS DATOS ARQUEOLÓGICOS RECUPERADOS DE LA EXCAVACIÓN

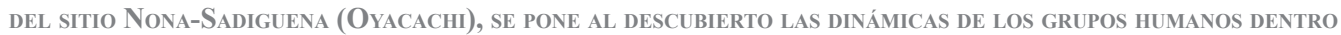
DEL PERÍODO “Formativo". LA EVIDENCIA DE SU CULTURA MATERIAL, DA CUENTA DE LA FUERTE INTERACCIÓN ENTRE GRUPOS DE ALDEAS ESTABLES Y GRUPOS MÓVILES CAZADORES-RECOLECTORES-CULTIVADORES, QUE APROVECHARON LOS RECURSOS PROVENIENTES DE DIVERSAS ECOLOGÍAS: ALTOS PÁRAMOS, VALLES INTERANDINOS, BOSQUES NUBOSOS Y SELVAS ALTAS, ASEGURANDO ASí SU COEXISTENCIA.

Palabras Claves: Cazadores recolectores cultivadores - aldeas estables - interacción andina-AMazónica La Chimba - Oyacachi - Periodo Formativo.

\section{Abstract}

This ARTICle is PART OF AN INVESTIGATION CARRIED OUT BETWEen THE ANDEAN AND AMAZON REGIONS, SPECIFICALLY in the area surrounding the Antisana and Cayambe volcanoes (Serrano, 2017). Under the model of EXCHANGE, INFERRED THROUGH ETHNO-ARCHAEOLOGY (RECIPROCAL EXCHANGE BETWEEN DOMESTIC UNITS) AND BASED

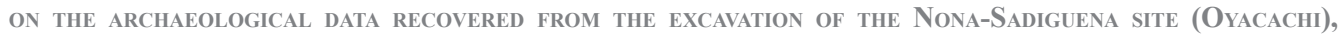
THE DYNAMICS OF THE HUMAN GROUPS WITHIN THE "FORMATIVE" PERIOD IS REVEALED. THE EVIDENCE OF MATERIAL CULTURE SHOWS THE STRONG INTERACTION BETWEEN STABLE VILLAGE GROUPS AND MOBILE HUNTER-GATHERERGROWER GROUPS, WHICH TOOK ADVANTAGE OF THE RESOURCES COMING FROM DIFFERENT ECOSYSTEMS: HIGH PARAMOS, INTER-ANDEAN VALLEYS, CLOUD FORESTS AND HIGH JUNGLES, THUS ENSURING ITS COEXISTENCE.

Keywords: Cultivating gatherers-hunter - Stable villages - Andean-Amazonian interaction - La Chimba - Oyacachi - Formative Period.

* Licenciado en Antropología con mención en Arqueología por la PUCE, maestro en Arqueología del Neotrópico por la ESPOL y es director del departamento de Arqueología en Sacharxeos. Sus estudios se han realizado en la sierra norte y buena parte de la Amazonia Ecuatoriana. Correo electrónico: supremoelder@hotmail.com. 


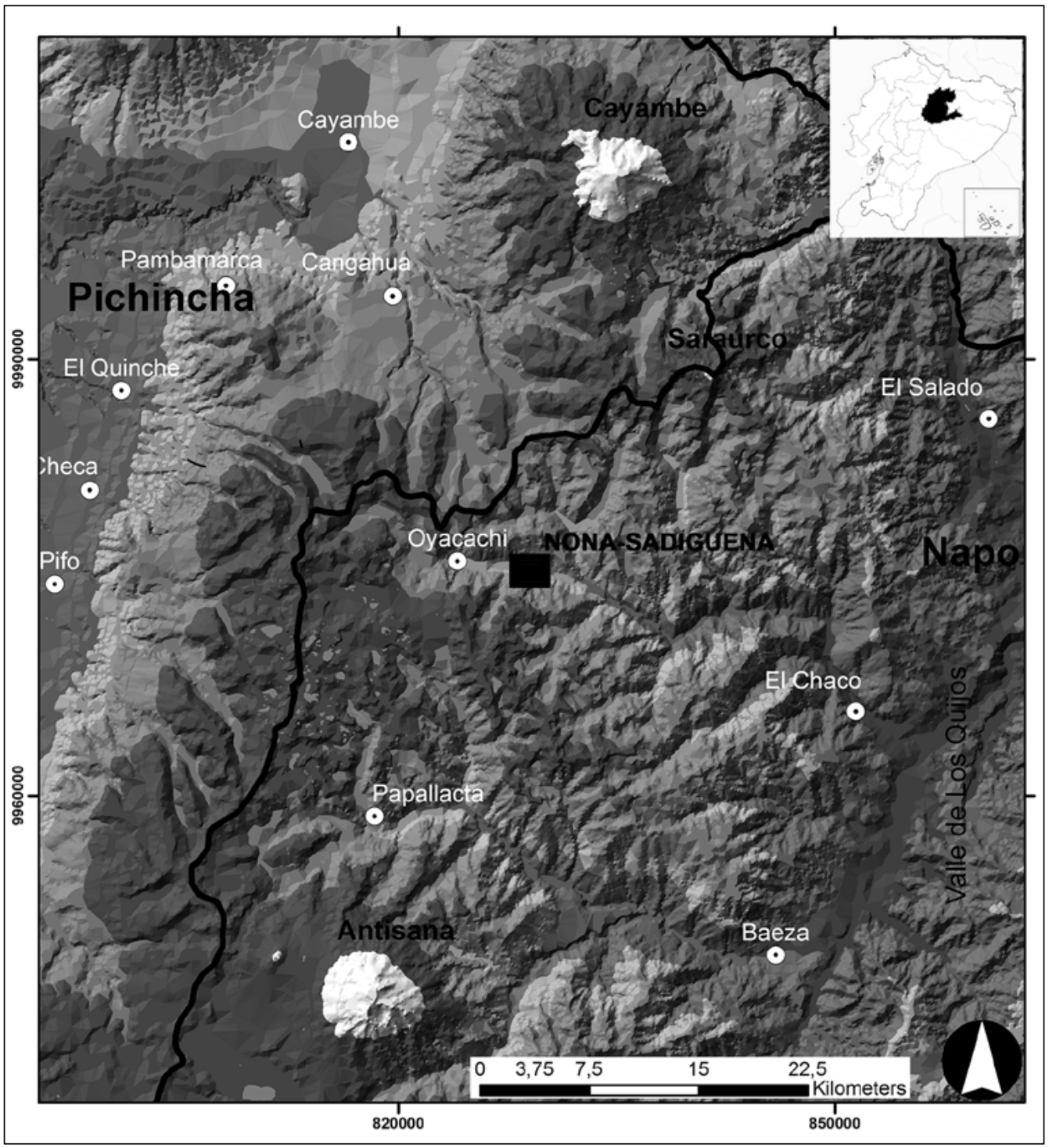

MAPA 1. Regiones de ESTUdio y ubicación del Sitio inVestigado. Elaborado por G. López. 


\section{Introducción}

$\mathrm{E}$ 1 intercambio en la Sierra Norte del Ecuador, entre Andes y Amazonía, ha sido inferido en gran medida a partir de la documentación etnohistórica y la presencia de la cerámica Cosanga en el período de Integración (500-1500 d.C.), atendiendo a comerciantes o mindalaes que se encargaban de traer productos desde las selvas orientales hasta los valles interandinos (Salomon, 2011; Bray, 1995; 2003; 2005). Lamentablemente, estos datos no han sido contrastados para los demás períodos, ni con evidencia arqueológica regional ni con el registro de las posibles rutas entre ambas zonas. Bajo este contexto, Serrano (2017) ha desarrollado varios modelos de intercambio a lo largo de la historia precolombina, mediante el uso de datos provenientes de la etnoarqueología, junto con evidencia arqueológica, geológica, geoquímica y paleo ecológica, que han puesto al descubierto una perspectiva de complejidad, basada en motivaciones sociales para comprender el intercambio interregional.

Tomando como punto de partida estos aportes, se presenta aquí información arqueológica del sitio Nona-Sadiguena de Oyacachi, un área nunca antes excavada, detallando datos culturales y cronológicos. Además, se pone en contexto toda la evidencia arqueológica proveniente de varias investigaciones en Andes y Amazonía, y se presenta el trazo y registro hecho mediante caminatas, de las posibles rutas que articulan estas dos regiones.

De este modo, se propone que en Oyacachi, existieron grupos móviles de cazadoresrecolectores-cultivadores y que el intercambio entre Andes y Amazonía, para el Holoceno Medio, giró en torno a relaciones sociales entre unidades domésticas fuertemente cohesionadas. En este sentido, los grupos móviles, habrían jugado un papel importante hacia el este de los Andes por encontrase cerca a los principales flujos de obsidiana, donde se avizora diversidad en los desarrollos culturales en una perspectiva comparada con los valles interandinos.

\section{Nuevas evidencias arqueológicas en los bosques nubosos de Oyacachi}

El valle de Oyacachi es desconocido por la arqueología ecuatoriana, ya que ha sido considerado como una zona de difícil acceso y "vacía". Se han hecho sólo algunas referencias generales, la primera viene de Porras (1975), quien mediante fotografías, dio a conocer la presencia de cerámica Cosanga, estelas antropomorfas y terracería habitacional típica de esta cultura. Más tarde, Echeverría (1998), registró sitios asociándolos también a la cultura Cosanga. Desde entonces, no se realizaron más investigaciones, hasta que Serrano (2017), excavó el Sitio Nona-Sadiguena y definió las diversas ocupaciones mediante fechados radiocarbónicos, tefrocronología y análisis de materiales culturales.

Este sitio Nona-Sadiguena responde a una serie de terrazas de roca de mica-esquisto dispuestas en una pendiente a 3100 m.s.n.m. Se encuentra a la margen sur del río Oyacachi cubriendo una superficie de tres hectáreas. En primera instancia, se realizó una prospección con pruebas de pala de hasta $120 \mathrm{c} . \mathrm{m}$. de profundidad, que demostró mayor densidad de material cultural sobre un pequeño promontorio (Mapa 2a) que comprende la parte menos afectada por la ganadería y construcción de acequias. Posteriormente, se plantearon cuatro unidades de excavación (Mapa 2b), con el fin de obtener datos más detallados sobre las ocupaciones que se revelaron en la prospección. 


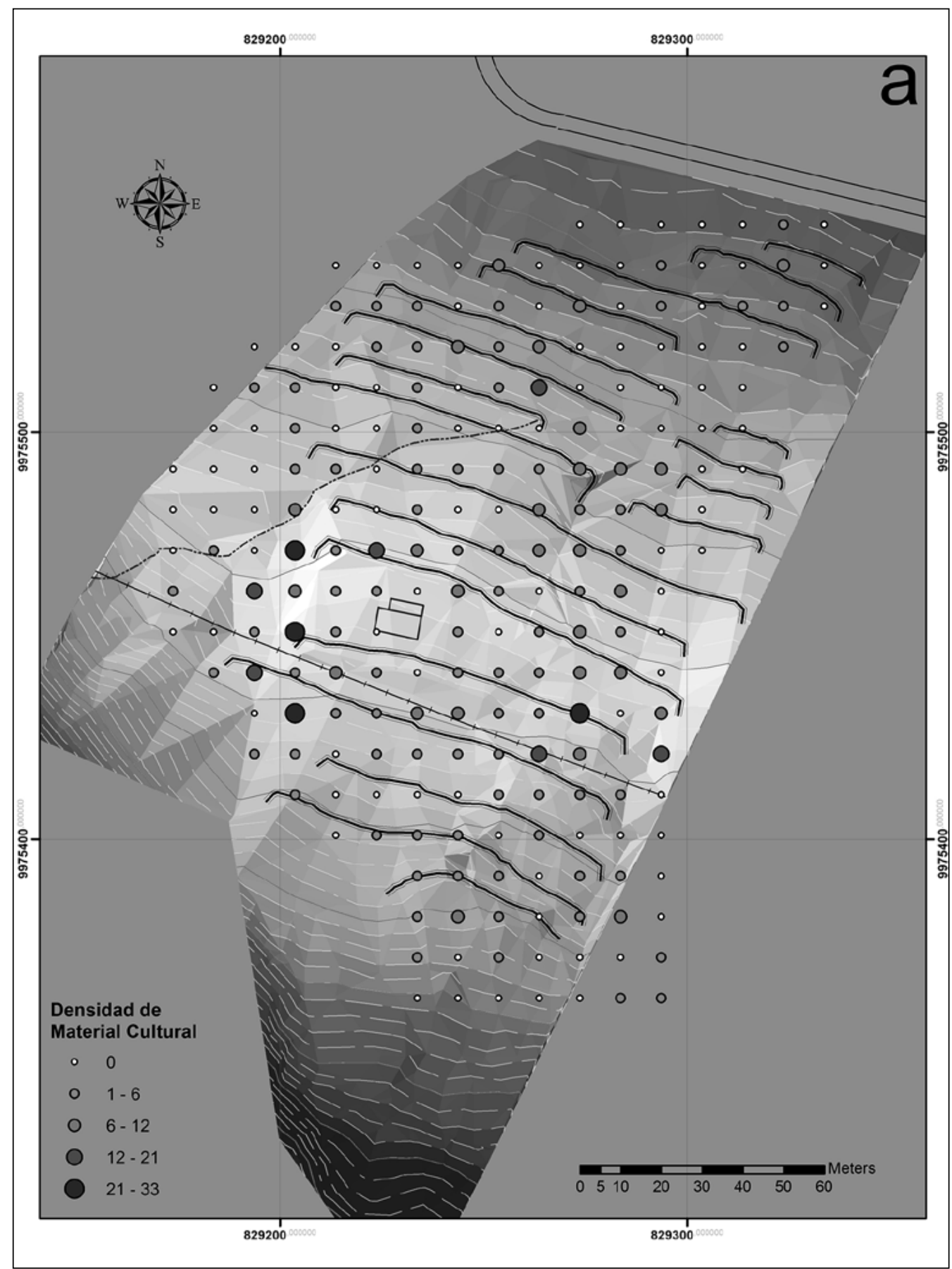

MAPA 2. Planimetría del sitio: A) prospección, pruebas de pala. Elaborado por G. López y F. Rodríguez. 


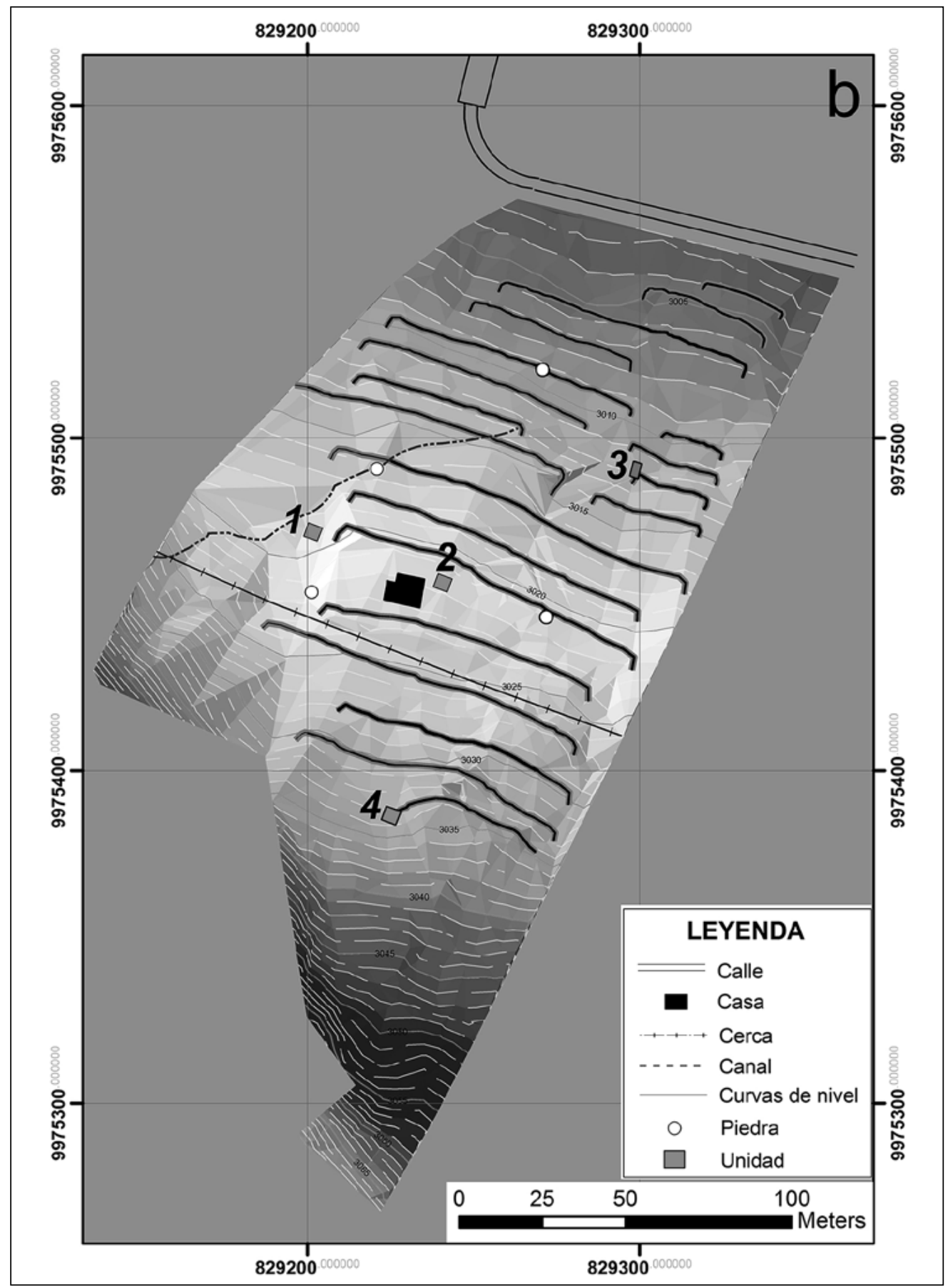

MaPa 2. Planimetría del sitio: B) unidades de excavación. Elaborado por G. López y F. Rodríguez. 
A la par, se registró un perfil expuesto en una de las terrazas del mismo sitio, para caracterizar la estratigrafía general (Fig. 1a) y corroborarla con las unidades de excavación (Fig. 1b). Estos datos dieron luces sobre el proceso de formación del sitio y de las vertientes escarpadas de la cordillera Real, que por su geomorfología, están expuestas a constantes derrumbes cuando hay demasiadas lluvias, lo que genera que la matriz metamórfica (material parental), suelos y vegetación en las partes altas, sean poco estables, pudiendo descender a las partes bajas, cercanas a los ríos, donde están los asentamientos humanos. Precisamente en julio de 2015, se presentó un suceso parecido que afectó al 30\% de las viviendas del poblado de Oyacachi (Fig. 1c línea roja depósitos coluviales), dando la pauta para pensar que este tipo de eventos en el pasado, pudieron haber desaparecido el registro arqueológico de las ocupaciones más tempranas, dejando solo pocos espacios no perturbados que conservarían este tipo de evidencia.

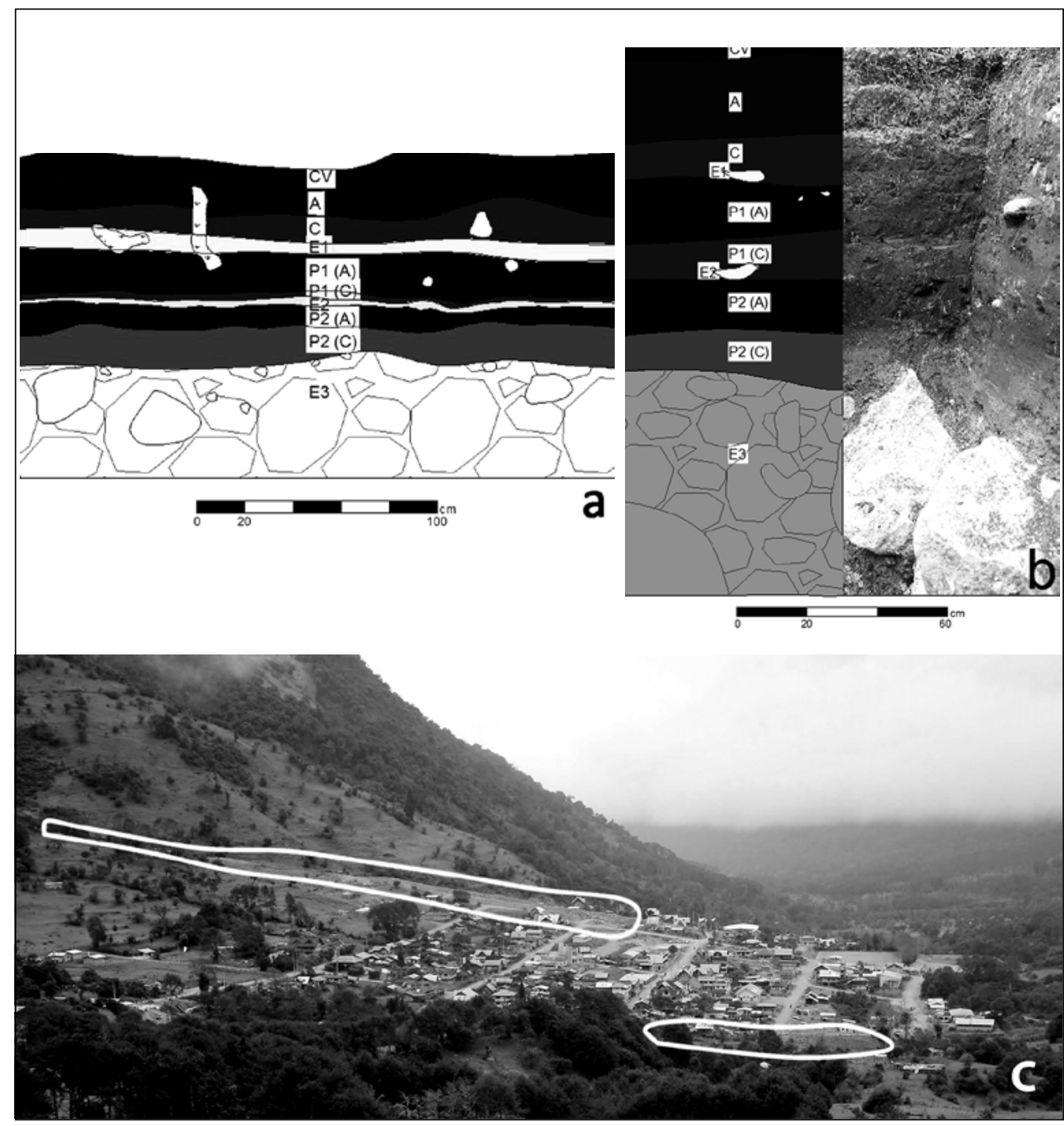

Figura 1. A) Estratigrafía general del sitio (Elaborado por G. López); B) Perfil Norte Unidad 1 (Elaborado por G. López); C) Depósitos coluviales actuales (Fotografía del autor). 
En el perfil registrado (Fig. 1a), justamente, se pudo observar depósitos coluviales antiguos (E3), sobre los cuales evolucionó un suelo con sus respectivos horizontes (P2C arcilloso y P2A orgánico). Arriba de éstos, se depositó una ceniza volcánica, la cual fue analizada petrográficamente, resultando minerales como Plagioclasa, Hornblenda, Cuarzo, Augita, Magnetita y agregados líticos de origen dacítico, que concuerdan con la capa guía de la erupción del Complejo Volcánico Pululahua, hacia el 2485 AP o 485 a.C. (Valverde, 2016). Sobre esta tefra evolucionó otro suelo y sus horizontes (P1C arcilloso y P1A orgánico), los cuales también fueron sepultados por una ceniza, ésta del volcán Quilotoa (Ibíd., 2016), fechada hacia el 1250 d.C. (Serrano, 2017) y arriba de la cual se evidencia un último horizonte (A limo arcilloso).

De acuerdo a la estratigrafía y las excavaciones, se propuso siete ocupaciones que inician después del último deposito coluvial (E3) hasta el horizonte A en la actualidad, con sus respectivas bioturbaciones que denotan material extrusivo e intrusivo, sin que esto rompa las tendencias del material cultural en la estratigrafía. Tal como se aprecia en la seriación cerámica (Fig. 2), sobre el depósito coluvial (E3), aparece cerámica de La Chimba (P2A), seguida por cerámica Bermejo (P1C), Cosanga I (P1C y P1A), Cosanga II y Caranqui (P1A), Caranqui y Colonial (A), y aunque no hay cerámica de los oyacacheños, se está al corriente por documentos escritos, que estuvieron asentados en la zona antes del 1500 d.C. a la actualidad.

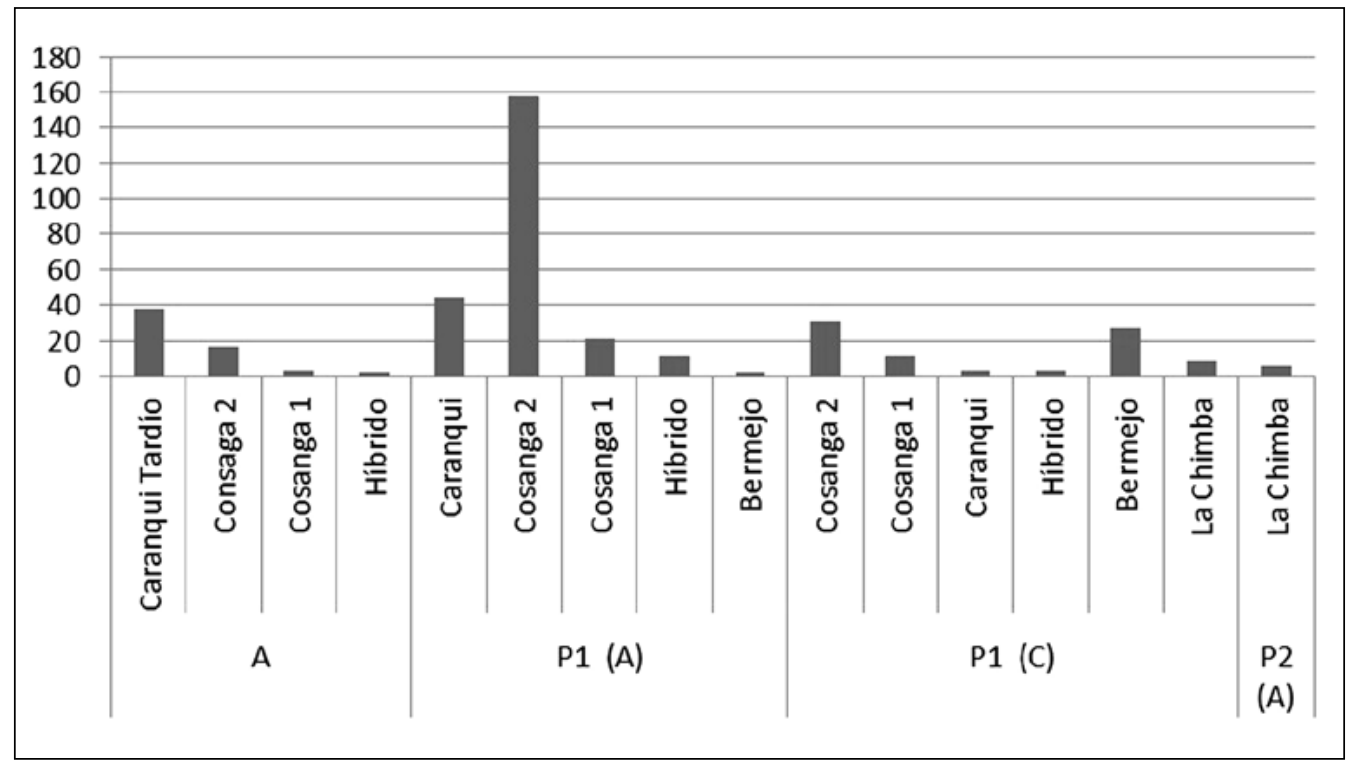

FIGURA 2. Seriación Cerámica por horizontes de SUelo. Elaborado por El aUtor.

\section{La cultura material de los grupos móviles del este}

Cerámica.- En cuanto a la cerámica, es limitada, 40 fragmentos de los cuales 14 son diagnósticos y relacionables con el material de La Chimba, disperso en el norte de Pichincha y gran parte de Imbabura (Athens, 1979; Montalvo, 2016). En Oyacachi, estos alfares presentan acabados simples con alisados al interior y exterior. En pocos casos han sido pulidos o recubiertos con baños de engobe rojo. La cocción de la pasta es reductora en la mayoría de los casos y parcial oxidante en menor proporción. Respecto a su materia prima, se vinculan bastante bien con arcillas de origen reciente (Holoceno, por estar bajo cenizas del Pululahua), localizadas en Oyacachi, en la zona de Maucallakta. 
Los desgrasantes de esta arcilla y cerámica son propios de su fuente, pudiendo relacionarse con proporciones considerables de Albita y en menor cuantía, con inclusiones de Cuarzo, según los datos de Difracción de Rayos X (DRX) de estas arcillas (Serrano, 2017). Las Plagioclasas como la Albita, se encuentran principalmente en las cangahuas u horizontes B y C de suelos arcillosos, que evolucionan a partir de cenizas volcánicas o material andesítico, como los existentes en ciertas partes de Oyacachi. Cisneros (2008) y Romero (2011), han logrado evidenciar esto, mediante sus análisis de DRX de los fragmentos cerámicos y suelos arcillosos de La Florida y Cayambe. Además de la fase principal de la Albita, se podrían incluir fases secundarias como la Magnetita, Fayalita, Hematita, Olivino y Zeolita, minerales típicos de ambientes volcánicos de los valles interandinos y sub-páramos.

En cuanto a formas cerámicas de La Chimba en Oyacachi, sobresalen cuencos, un pico de botella y una base anular de cuenco (Fig. 3a). Casi todos los restos cerámicos de este grupo son bastante burdos y toscos, similares a los encontrados en Guachalá (Cangahua) y Tababela, sitios cercanos a Oyacachi.

Las botellas son típicas del periodo "Formativo", comunes en Cotocollao (Villalba, 1988), La Chimba (Athens, 1979), Tababuela (Echeverría y Berenguer, 1995), Tababela (Aguilera, 2009) y Las Orquídeas (Montalvo y Dyrdahl, 2014). Montalvo (2016), ha realizado un análisis exhaustivo de la cerámica de La Chimba en Las Orquídeas, comprobando que las botellas con apertura estrecha y alargada, vertical con perfil troncocónico y borde directo con labio redondeado o aplanado (Fig. 3b), están presentes en las ocupaciones tempranas de los estratos 16 y 22, que están fechados entre el 800 y 750 a.C. El pico de botella de Oyacachi, guarda similitudes muy estrechas con los picos de botella analizados de Las Orquídeas (Montalvo, C, comunicación personal, 2016), y por lo tanto, deberían tener una datación parecida, contando que el material fue hallado en el paleosuelo 2, bajo la tefra del Pululahua, es decir, corresponden a una fecha anterior al 485 a.C.
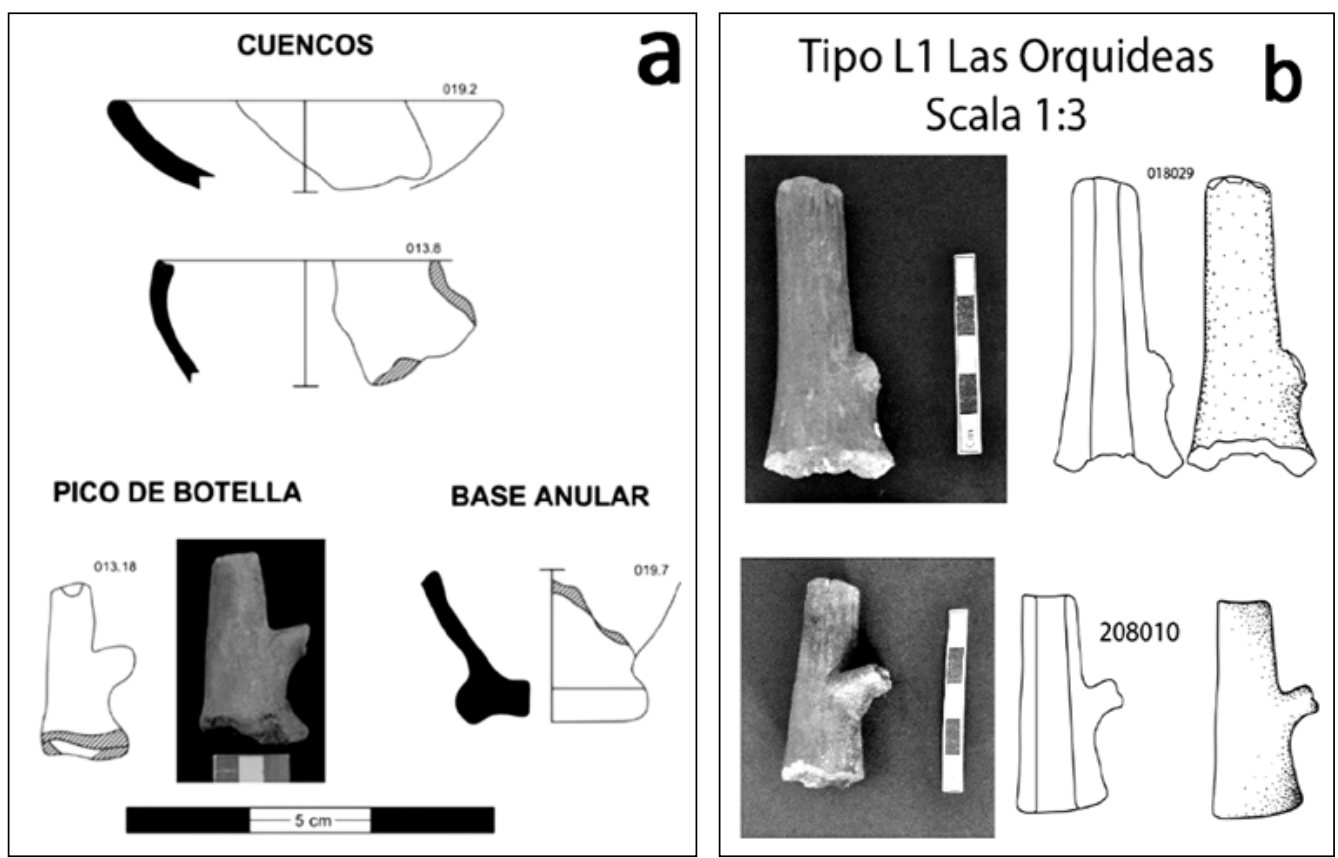

Figura 3. A) Formas cerámicas de La Chimba en Nona-Sadiguena. (Elaborado por G. López y O. Pozo); B) Picos de botella de las Orquídeas. Fotos de Daniele Deidda y Pablo Quelal, dibujos de Cristina Tavolini y Carlos Montalyo, tipología de Carlos Montalvo (2016). 
Lítica.- En cuanto a las herramientas líticas, la evidencia es más consistente que la cerámica, ya que se reportó un total de 175 objetos diagnósticos (Fig. 4), claramente poscionados bajo la tefra del Pululahua. En general, la industría lítica esta manufacturada en obsidiana, basalto, esquistos cristalinos y muscovíticos, andesitas y cuarzo. En su mayoria, existen artefactos informales como lascas y láminas utilizadas, descarte en núcleos unidireccionales, yunques y herramientas formales en raspadores espesos, que quizá denotan trabajos vinculados con fibras vegetales, maderas y procesamiento de productos recolectados.

Respecto al uso de obsidiana, se aprecia una amplia movilidad, ya que mediante los analisis de Fluorescencia de Rayos X (XRF) realizados por Dyrdahl (2017), se identificó obsidiana de varias fuentes: Mullumica Fe bajo $(n=1)$ y Gap Mullumica $(n=2)$, seguido del tipo CallejonesMullumica Fe alto $(n=2)$, "La Chimba" $(n=2)$ y Callejones Fe bajo $(n=1)$. Así mismo, se tomó siete muestras de cantos rodados de obsidiana del río Oyacachi, dando como resultado "La Chimba", con lo cual, la fuente de esta obsidiana, parecería encontrarse en Oyacachi.

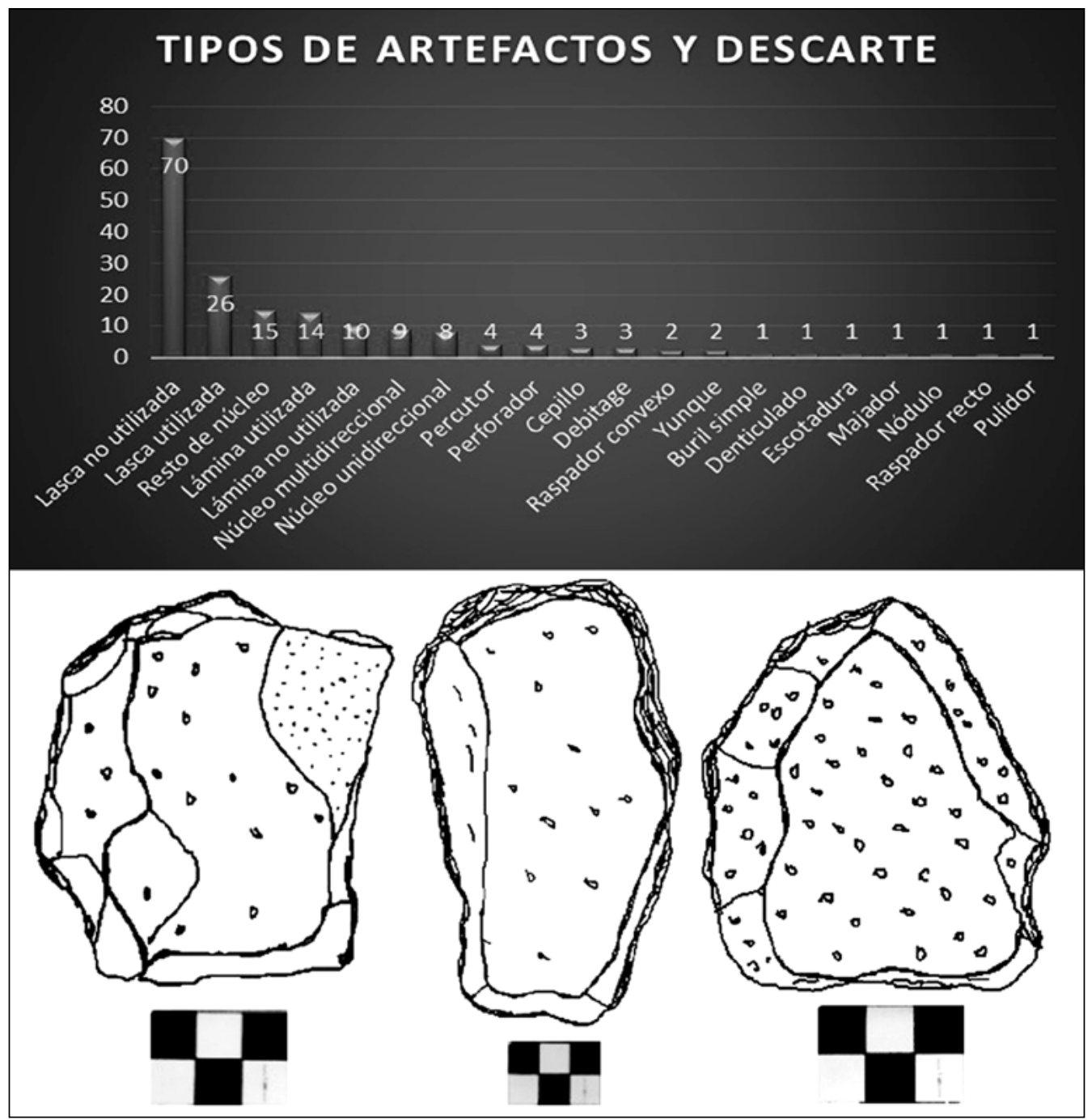

Figura 4. Tipología lítica y raspadores de La Chimba en Nona-Sadiguena. Elaborado por el autor. 


\section{Cronología relativa y absoluta}

En lo que se refiere al sitio Nona-Sadiguena, la fecha tentativa para las ocupaciones del "Formativo", giraría entre el 800-485 a.C., que son fechas que encajan con las calibraciones realizadas para sitios contemporáneos (Fig. 5), anteriores a la caída de ceniza del Pululahua. Esto se basa también en el suelo poco desarrollado que presenta la ocupación y que sugiere el retraso de al menos 100 a 300 años antes de la caída de esta tefra. Hacia el 800-500 a.C., se reporta cerámica de La Chimba en Tababela. Unos cuantos fechados asociados a artefactos líticos de Puerto Napo, Tena y el valle de los Quijos, se ubican en el mismo rango de tiempo, entre el 796 -552 a.C., con una media en el 665 a.C., un promedio bastante bueno si se compara con los fechados obtenidos en Las Orquídeas (Imbabura) para la misma cerámica, ubicados entre el 800-400 a.C.

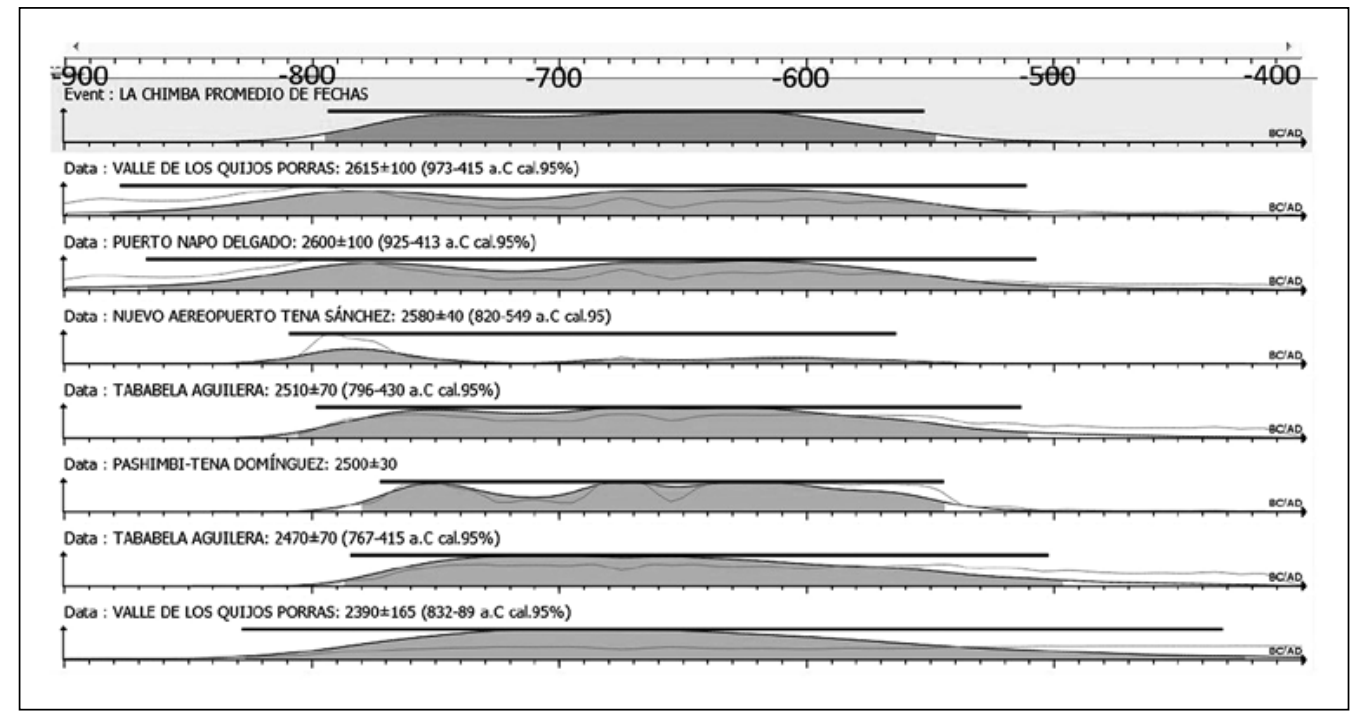

Figura 5. Calibración de fechas asociadas a la Chimba. Elaborado por el autor.

Los fechados anteriores, comprendidos entre el 1400-800 a.C., se encuentran más hacia las zonas de selva alta, en donde no ha habido derrumbes constantes como los que se registran en las vertientes escarpadas y que, como se ha dicho, pudieron desaparecer la evidencia de los grupos más tempranos (Revisar cuadro cronológico de Serrano, 2017).

\section{Hacia una perspectiva integral de los Andes y Amazonía (1400-400 a.C.)}

Con la evidencia de zonas como Oyacachi, antes consideradas vacías, el panorama toma otro sentido y permite advertir la interacción entre dos modelos de subsistencia alternos y complementarios: grupos sedentarios-ceramistas y grupos móviles cazadores-recolectores. Es así que se propone no llamar "Formativo" a este periodo, ya que su conceptualización en cuanto a la formación de algo, no parece responder claramente a datos arqueológicos y más bien invisibiliza a los grupos sin cerámica del este así como sus espacios de influencia, sino periodo de "Grupos Móviles y Sedentarios".

En este periodo, en el Occidente (Pichincha e Imbabura), es posible ver aldeas estables con unidades domésticas agrupadas, centros de producción artesanal, dependencia de la agricultura y clara evidencia de cerámica estilizada (Villalba, 1988; Domínguez, 2009; Montalvo y Dyrdahl, 
2014). Por otro lado, y mediante la evidencia arqueológica en Oyacachi y grupos a-cerámicos al Este, las sociedades cazadoras-recolectoras continuaron viviendo en los altos páramos, valles interandinos, bosques nubosos y selvas tropicales, y complementaron las economías de los grupos sedentarios y ceramistas (Serrano, 2017).

En el caso de los valles interandinos, el sitio mejor definido para esta época es Cotocollao, fechado hacia el 1500 a.C., aunque esta fecha ha sido cuestionada por Ugalde (2014), pues en el sitio Rancho Bajo, se descubrió un cementerio y talleres de obsidiana sin cerámica, bastante bien fechados entre el 1600-1440 a.C., con lo cual Cotocollao, debería posicionarse hacia el 1400 a.C. Además, la estratigrafía del sitio confirmaría que Rancho Bajo es anterior a Cotocollao.

De acuerdo a las investigaciones de Marcos et al. (2002), se ha sugerido también la presencia de una cerámica más temprana, denominada Mogote, que estaría fechada entre el 1800-1600 a.C., y que presumiblemente por el análisis de pastas, se encontraría en un lugar cercano a la meseta de Quito que aún no ha sido excavado, pudiendo estar incluso en las vertientes occidentales de la cordillera Occidental, donde afloran arcillas de origen volcánico. Esto ha sido planteado en base a un análisis petrográfico que demuestra la existencia de minerales volcánicos como Plagioclasas, Hornblenda, Augita, Olivino y Pumitas en la cerámica Mogote encontrada en Valdivia, lo cual sugiere que su fuente próxima, debe estar en un ambiente volcánico. De ser cierta la existencia temprana de Mogote, representaría contactos más estrechos de grupos ceramistas de Occidente (Mogote y Nambillo Temprano) con cazadoresrecolectores-cultivadores del altiplano de Quito, grupos que abundaban en toda la Sierra Norte, y por lo tanto, Cotocollao podría ser la transfiguración étnica de Nambillo Temprano, Mogote y cazadores-recolectores-cultivadores que estuvieron en constante interacción.

Por otro lado, en Imbabura, está la cerámica de La Chimba, encontrada a los pies del nevado Cayambe, en Las Orquídeas (Ibarra), Urcuquí, Cotocollao, y el nuevo aeropuerto de Quito, datada hacia el 900-400 a.C. Los pobladores de La Chimba habrían explotado los sistemas montañosos orientales, por la amplia presencia de obsidiana y restos fáunicos de animales de la cordillera Oriental (Athens, 1979 y Athens, 1990). De igual forma, habrían, establecido relaciones comerciales más estrechas con los grupos del pie de monte occidental y las sociedades costeras de Santa Elena, Manabí y Esmeraldas, por la evidencia de concha spondylus, madre perla, cerámica costeña y oro (Montalvo y Dyrdahl, 2014).

Para el caso de la provincia de Napo y Orellana, la cerámica es escasa y se la encuentra asociada a utillajes líticos en las partes altas (Oyacachi), filiada a la de La Chimba. Lo mismo sucede en regiones más bajas como en el valle de los Quijos (Cuéllar, 2009) y Puerto Napo (Delgado, 1999), donde se halló picos de botella y cerámica burda asociada a artefactos líticos. Esto es de esperarse, ya que al ser grupos móviles, la cerámica no era indispensable, pues estos grupos basaban su economía en el cultivo de plantas, caza y recolección. En este sentido, los datos sugieren que hacia el Oriente, el modelo de caza-recolección y cultivo de plantas era el preferido. De todas maneras, habría que indagar más sobre las sociedades sin cerámica en el Oriente norte para ahondar en esta idea.

En cuanto a los caminos o rutas registrados entre Andes y Amazonía, es viable pensar que las relaciones entre los grupos de sus diferentes ecologías, aumentaron, o en su debido caso, los bosques montanos altos y páramos se explotaron con mayor intensidad. Este supuesto se basa en la evidencia de climas secos y húmedos, así como en la presencia de fuegos antropogénicos en zonas altas, acompañados de una disminución de bosques de Polylepis, principalmente en el sector austral del Ecuador (Villota et al., 2014). También se han hecho reportes en el valle de Anteojos, cordillera Oriental de la provincia de Cotopaxi (Ibíd., 2014, 113 - 114) y hacia el norte, en Guandera (Carchi), con fechados de carbones realizados por de Di Pascale (2008), que podrían estar sugiriendo la misma evidencia. Para el caso concreto de la zona de estudio, Van der Hammen et al. (2003: 258), reportan el mismo patrón en Mullumica, aunque con alternancias de climas secos y húmedos por la presencia de Lycopodium, Polylepis y gramíneas. 


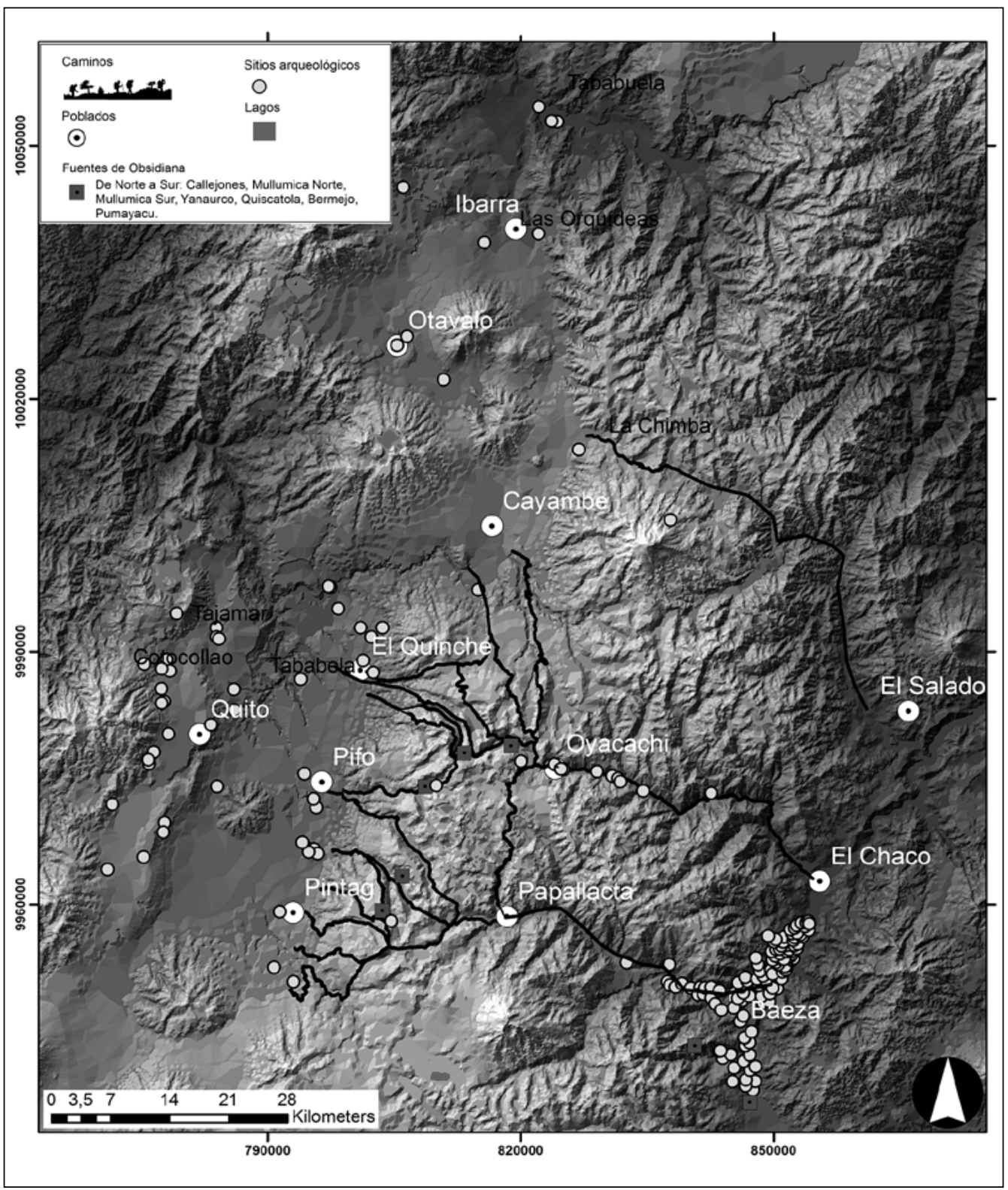

MAPa 3. Caminos y sitios de Grupos Móviles y Sedentarios (1400 a.C. - 400 a.C.). Elaborado por G. LÓPEZ CON INFORMACIÓN DEL AUTOR. 
Señalan, además, variaciones considerables de Polylepis y presencia de Chenopodium quinoa que responderían al impacto realizado por habitantes locales o temporales en los altos páramos, que utilizaban Polylepis como combustible maderable y quinoa como alimento.

Este impacto es presumible, ya que en este periodo, la obsidiana de los altos páramos era demandada en mayor cantidad, con lo cual, los pobladores no se habrían contentando con los nódulos pequeños que trasportan las fuentes secundarias de Mullumica, Yanaurco, Quiscatola y Callejones; y más bien habrían preferido las fuentes primarias. Esta evidencia se sustenta por la gran cantidad de objetos líticos encontrados en las aldeas estables de Cotocollao, Tajamar, Tababela, Las Orquídeas y La Chimba. Asimismo, los artefactos líticos retocados, suelen ser de mayores dimensiones (4 x 6 c.m.), según los análisis de Villalba (1988) para Cotocollao y de Montalvo y Dyrdahl (2014) para Las Orquídeas.

Por los análisis de Fluorescencia de Rayos X, efectuados por Asaro et al. (1994) y Dyrdahl (2014 en Ugalde, 2014), se sabe que estos pueblos obtenían la obsidiana según su proximidad a las fuentes, por ejemplo, en Cotocollao, hay preferencia por la variedad Mullumica Fe bajo y en Las Orquídeas, por Callejones Fe bajo, mientras que, las obsidianas de Yanaurco-Quiscatola y Mullumica-Callejones Fe alto, son complementarias, con la particularidad que en el sitio las Orquídeas, Yanaurco-Quiscatola está ausente y la variedad La Chimba hace su aparición en mínimas cantidades. No así en el sitio La Chimba, donde es mayoritaria la variedad de Callejones Fe bajo, complementada con obsidiana de La Chimba y no hay evidencia alguna de Yanaurco-Quiscatola ni Mullumica.

En este sentido, surge la posibilidad de que alguien movilizó estas materias y no los propios habitantes de estos poblados, ya que las distancias son considerables: $40 \mathrm{Km}$. en línea recta desde Cotocollao hasta el flanco Sur de Mullumica y $65 \mathrm{Km}$. desde las Orquídeas hasta Callejones. Además, entre estos sitios y los flujos de obsidiana hubo otros poblados, caseríos y campamentos con gente interactuando, que fueron los nexos para concretar los intercambios y que no deberían ser invisibilizados por una arqueología poco interpretativa y regional de la zona.

Hasta hace 13 años, no se tenía reportes de más sitios arqueológicos del "Formativo", hoy en día se ha podido registrar y excavar nuevos yacimientos en los flancos occidentales de la Cordillera Real en: Cayambe, Tababela, El Quinche, Cusubamba, Checa, Pifo, Pintag (Bray, 2003; Villalba, 2005; Jara y Santamaría, 2009, Aguilera, 2009; Molestina, 2014). Por otro lado, en esta investigación se pudo excavar y fechar sitios filiados a La Chimba en Oyacachi, un lugar algo alejado de los valles interandinos; así pues, la adquisición directa de esta materia y otras, no tiene mayor cabida y debe ser vista entorno a gente interactuando en espacios que antes se consideraban "vacíos, naturales, prístinos o vírgenes".

En este plano, es de esperarse que la obsidiana y otros productos como vegetales, frutos recolectados, plantas medicinales, presas de caza, tecnologías y conocimientos mágicos religiosos, pudieran ser intercambiados entre estos pobladores a través de la red de caminos registrada (Mapa 3). Para el caso, se ha creído pertinente aplicar el modelo de intercambio recíproco entre unidades domésticas (Serrano, 2017), el cual es inferido a partir de tres evidencias arqueológicas: obsidiana, cerámica de La Chimba y enterramientos sin cerámica en los poblados sedentarios de Cotocollao y Tababela.

\section{Intercambio recíproco entre unidades domésticas}

Este modelo concibe el intercambio en base a unidades domésticas que se encuentran filiadas culturalmente. En este sentido, la relación de sitios de distintos pisos ecológicos permite la articulación de varias regiones. De este modo, las materias primas, tecnologías, conocimientos y productos viajan de manera efectiva y eficiente al articularse con poblados y unidades domésticas emparentadas culturalmente y por alianzas de parentesco (Serrano, 2017). 
Obsidiana.- Respecto a las materias primas como la obsidiana, hubo una mayor demanda de ésta por las dimensiones mayores de los soportes y por la gran cantidad de núcleos agotados en Quito e Ibarra. Este comportamiento sugiere que los pobladores de estas aldeas requerían bloques más grandes de obsidiana, pero a su vez, los agotaban porque no los tenían cerca. Por este motivo, alguien móvil tenía que encargarse de esta tarea, alguien que conocía las rutas, los páramos y las fuentes. En este caso, pudo haberse tratado de cazadores como los de Oyacachi y Papallacta que explotaban las zonas altas y posiblemente, estaban emparentados con los de las aldeas ceramistas de La Chimba, Cotocollao y otras bandas de cazadores de los valles interandinos, próximos a la Cordillera Oriental.

Desde aquí, a través de otros cazadores o de los mismos individuos filiados a grupos ceramistas de Cotocollao y la Chimba, pudieron haber proveído de obsidiana a los centros productivos asentados al este la cordillera Occidental. Esto se plantea debido a que las industrias líticas de los poblados de este período en Pifo, Pintag, y Tababela, no tienen gran cantidad de obsidiana (200600 objetos) por unidades muestreadas como los de la Chimba (20.000), Cotocollao (25.000), Tajamar (2.500) y las Orquídeas (120.000). Al parecer, en las zonas cercanas a las fuentes, se explotaba solo lo necesario y los bloques sin corteza se los llevaba al oeste. Así, los pobladores de Cotocollao y las Orquídeas, utilizarían estas materias en sus actividades artesanales y de igual manera, los bloques medianos, los habrían intercambiado con los pobladores del pie de monte occidental como los de Palmira (Noroccidente de Pichincha), donde se reducían los núcleos al máximo, y los soportes de éstos, se los intercambiaba con otras sociedades de foresta tropical, llegando de 10 a 20 lascas a los poblados costeros (Serrano, 2016a) en Santa Elena, Manabí, Esmeraldas y los pueblos de la Sierra Sur (Salazar, 1992; Burger et al., 1994). En cuanto a las obsidianas locales de Cosanga, habrían sido utilizadas entre los grupos móviles de selvas altas de los Quijos, Tena y Orellana.

Enterramientos a-cerámicos.- Por otro lado, se sugiere los enterramientos sin cerámica en Cotocollao y Tababela, fechados entre el 1200-500 a.C. (Fig. 6). Aquí se aprecian enterramientos humanos individuales y también masivos como los reportados por Ugalde (2014) en Rancho Bajo y que se asocian bastante bien con los excavados por Villalba (1988). De igual manera, están los de Tababela, reportados por Molestina (2014), donde se observan rasgos comunes como: ausencia de cerámica, cantos rodados a manera de ofrendas y bloques de cangahua naturales y preparados que delimitan el espacio (Torres, 2014). Al parecer, podría tratarse de rasgos de enterramiento compartidos del periodo Tardío de los cazadoresrecolectores-cultivadores y tal como se lo habría presumido, pudieron tener fuertes vínculos con sociedades ceramistas del pie de monte occidental que, de a poco, se asentaban en los valles de Pichincha e Imbabura.

En este sentido, los entierros sin cerámica en aldeas alfareras, representan quizá, la convivencia articulada y de alianzas entre dos grupos, donde los más móviles se encargaban de proveer recursos de la alta montaña como la obsidiana y de explotar sus ecologías. De igual forma, los grupos móviles sabían cultivar, aunque su subsistencia estaba direccionada hacia la caza y recolección. Como dato sugestivo de este comportamiento, está la evidencia paleobotánica analizada por Romero (2010) en los entierros sin cerámica de Tababela, donde se encontró restos microscópicos de plantas de recolección y cultivadas como: canastas con alimentos y recipientes hechos en puma maqui (Oreopanax), tapados con hojas de chilca (Baccaris latifolia), cuyo contenido fue chochos (Lupinus), izo (Coerulea), porotillo (Edulis), chirimote (Disterigma alaternoides), guayabo de monte (Viburnum anabaptista graebn) y maíz (Zea mais).

De igual forma, podría reproducirse este modelo en Imbabura, ya que hay la posibilidad de que los cazadores de las zonas altas de su Cordillera Occidental y Real, estuvieran interactuando y manteniendo relaciones matrimoniales con los grupos ceramistas de La Chimba. Así mismo, los de Cotocollao, pudieron haber establecido relaciones con éstos, por la evidencia dispersa de 

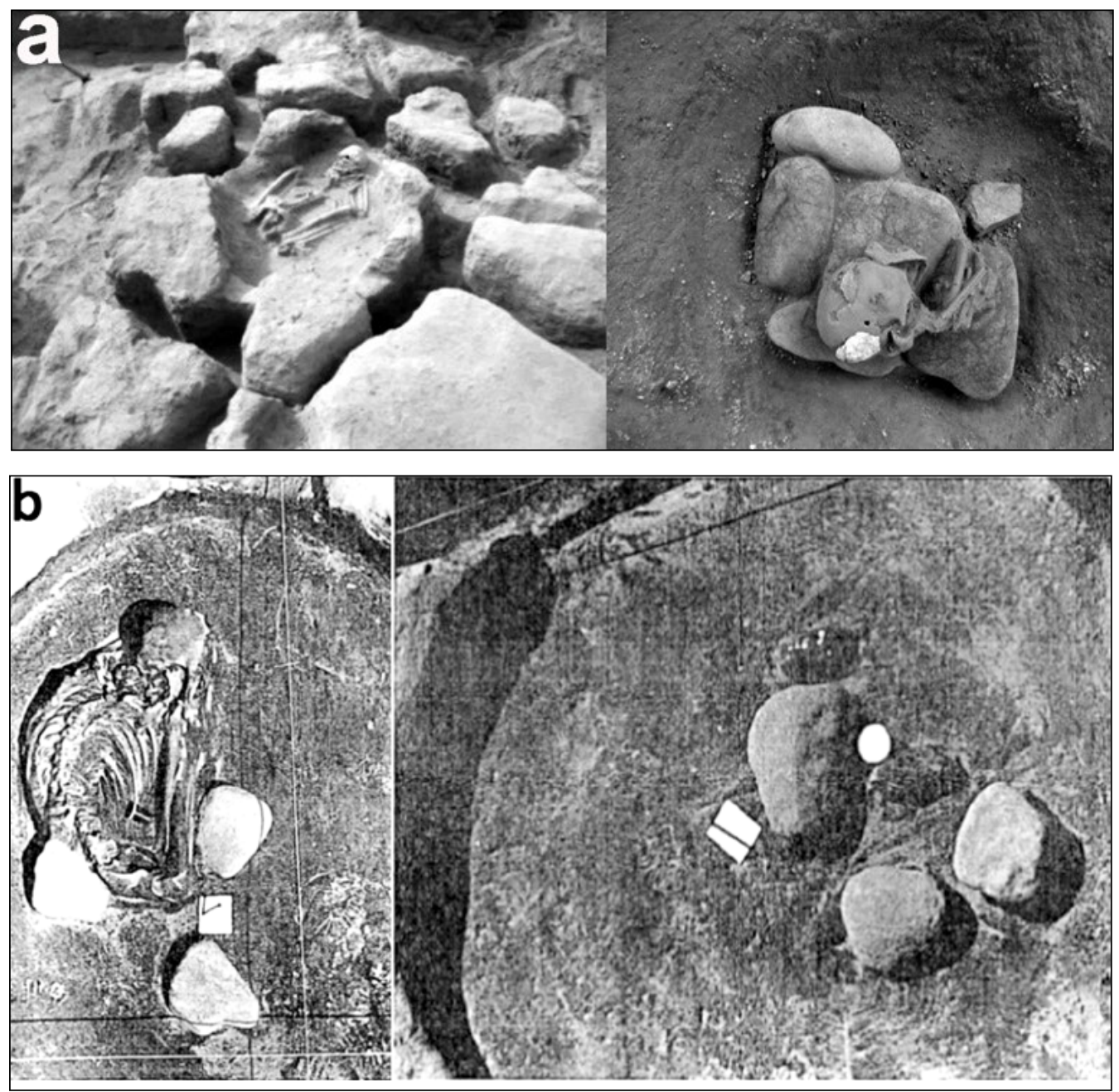

Figura 6. A) Sepulturas de Tababela sin cerámica y cantos rodados Sepultados (Molestina, 2014);

B) Entierro sin Cerámica y entierro de piedras con restos de dientes (Villalba, 1988).

su cerámica en Pichincha e Imbabura (Villalba, 1988; Ontaneda, 2010; Montalvo y Dyrdahl, 2014). Por otro lado, también se ha reportado cerámica Chorrera y Machalilla en Jardín del Este, Cotocollao y Las Orquídeas, lo cual quizá represente un vínculo más fuerte con Occidente, pero, por la presencia de obsidiana del este y de entierros sin cerámica, también hubo una fuerte relación con los grupos de Oriente.

A decir de estos datos concretos de Cotocollao y Tababela, a más de los intercambios recíprocos, también podría interpretarse como una forma de resistencia a perder el ethos de cazador y recolector. Quizá, en el sentido de lo que plantea Bonfild (1991) y Ribeiro (1974), la interacción también genera disputas en la imposición de tecnologías, modos de subsistencia y formaciones políticas. En este plano, la cerámica y la agricultura pudieron haber generado compulsiones con los modos de vida vigentes y a través del parentesco e imposición de la cerámica, los grupos móviles fueron transfigurándose a las culturas alfareras que aparecieron en este período y en los posteriores. 
Por otra parte, es factible que hacia los altos páramos se haya continuado con la caza y recolección, evidenciándose grupos o segmentos culturales que no eran del todo ceramistas o agricultores, pero que se relacionaban con los grupos étnicos de valles interandinos. Lamentablemente, la arqueología de este período en zonas altas y bajas ha sido escasa y ha habido una tendencia casi exclusiva a entender a los grupos ceramistas, por lo tanto, es indispensable comprender a todas las sociedades pasadas en base a la diversidad y elección que cada grupo tiene para desarrollarse e interactuar con otros.

Cerámica.- Al otro lado, en la Ceja Andina Amazónica y sus estribaciones hacia el este y selvas altas del Napo, la situación parece ser algo similar, aunque la recurrencia de la cerámica es un tanto escasa para esta época. Los únicos reportes de fragmentos diagnósticos asociados a ocupaciones discernibles son los de Oyacachi, filiados a La Chimba. En estas ocupaciones, es más común el trabajo en piedra que en cerámica, sobre todo para la fabricación de cepillos y raspadores para procesar maderas y vegetales. Este modo de vida, quizá pudo ser el elegido por los pobladores del Napo, quienes no precisaban de la cerámica para desarrollarse. Sin embargo, es posible evidenciar algunos fragmentos con engobe rojo excavados por Cuellar (2009) en el valle de los Quijos, que al hacer una comparación de cerámica, de hallazgos y de fechados, algunos de estos fragmentos no diagnósticos, se relacionan mejor con los de La Chimba, tal como se manifestó en la sección cerámica. Así mismo, Delgado (1999) reportó en el Tena y en el valle de los Quijos tres picos de botella que potencialmente se relacionarían con los grupos propuestos en Oyacachi.

Esto podría sugerir la existencia de un grupo cultural móvil que sabía hacer cerámica tosca y poco estilizada de La Chimba, pero que basaba su economía en la de grupos más móviles que cazaban, recolectaban y cultivaban. Podría tratarse, entonces, de una transfiguración entre grupos ceramistas de La Chimba y grupos móviles de las selvas altas del Napo, con lo cual, la articulación con la Amazonía habría sido mucho más estrecha.

Con este supuesto es posible proponer que los grupos filiados a La Chimba en Oyacachi, proveían obsidiana de Callejones y "La Chimba" a otros grupos asentados más hacia el oeste de la cordillera Real, que pudieron haber sido cazadores de los sub páramos de Cangahua, Gualimburo, Pisambilla, Moyabamba y Pambamarca, quienes a su vez, la distribuían a las aldeas de los valles de Pichincha e Imbabura, a través de intercambios recíprocos y matrimoniales. Las mismas relaciones habrían tenido un papel importante hacia el valle de los Quijos, solo que con productos vegetales, alianzas matrimoniales y saberes mágicoreligiosos. 


\section{Conclusiones}

Los datos arqueológicos presentados sugieren la existencia de grupos móviles con escasa cerámica en los bosques nubosos del este (Oyacachi) que estaban conviviendo e interactuando con grupos ceramistas de los valles interandinos. En la periodización tradicional ("Formativo"), estos grupos fueron separados en el tiempo, por una visión evolucionista. Como se puede observar, al oeste y oriente, existían relaciones muy estrechas con los distintos grupos, dando como fruto manifestaciones culturales diversas. Por un lado, los de Cotocollao estaban emparentados con cazadores de los altos páramos de Pintag y Pifo y por otro lado, los de La Chimba, habrían ido más hacia el este para vincularse con cazadores de los páramos, bosques nubosos y selvas altas de los Quijos, dando origen a una manifestación particular de La Chimba en tierras amazónicas.

Desde otra perspectiva, como se sugirió, hay la posibilidad de que esta interacción implique compulsiones y desplazamiento de grupos, lo cual podría evidenciar que la agricultura a mayor escala, la cerámica y el sedentarismo, hayan ganado popularidad en los modos de vida de la Sierra norte, mientras que las sociedades más móviles, pudieron continuar explotando zonas periféricas de los valles, posiblemente en el páramo y sub-páramo. Desafortunadamente, estos grupos han sido invisibilizados por una arqueología que ha privilegiado a la cerámica para proponer culturas arqueológicas, sin reflexionar sobre la existencia de modos de subsistencia diversos en otras ecologías. 


\section{Bibliografía}

Aguilera, M. 2009, Informe de Avance Rescate Arqueológico Terminal Complemento Oeste, INPC - CORPAQ, Quito.

Asaro, F. et al. 1994, "Ecuadorian Obsidian Sources Used for Artifact Production and Methods for Provenience Assignments", en: Latin American Antiquity, 5 (3), pp. 257-277.

Athens, J. 1979, El Proceso Evolutivo en las Sociedades Complejas y la Ocupación del Periodo Tardio, Abya-Yala, Quito.

Athens, J. 1990, Prehistoric Agricultural Expansion and Population Growth in Northrn Highland Ecuador: Intermin report for 1989 Filedwork, Informe para el INPC, Quito.

Bonfil, G. 1991, “La Teoría del Control Cultural en el Estudio de Procesos Étnicos”, en: Estudios sobre las Culturas Contemporáneas, 4 (12), Universidad de Colima, México, pp. 165-204.

Bray, T. 2005, "Multi-Ethnic Settlement and Interregional Exchange in Pimampiro Ecuador", en: Journal of Field Archaeology, 30 (2), pp. 119-141.

2003, Los Efectos del Imperialismo Incaico en la Frontera Norte, Abya-Yala, Quito.

1995, “The Panzaleo Puzzle: Non Local Pottery in the Northern Highland Ecuador", en: Journal of Field Archaeology, 22 (2), pp.137-156.

Burger, R. et al. 1994, “An Initial Consideration of Obsidian Procurement and Exchange in Prehispanic Ecuador", en: Latin American Antiquity, 5 (3), pp. 228-255.

Cisneros, P. 2008, Caracterización de Material Cerámico en los Sitios Arqueológicos “La Florida” y "Rumipamba” por las Técnicas de Absorción Atómica y Difracción de Rayos X, Universidad Central del Ecuador, Tesis para optar por el Título Profesional de Químico, Quito.

Cuéllar, A. 2009, Los Cacicazgos Quijos: Cambio Social y Agricultura en los Andes Orientales. Pittsburgh, Universidad de Pittsburgh, Estados Unidos.

Delgado, F. 1999, Proyecto de Desarrollo del Campo Villano - Fase de Construcción. Prospección, Rescate y Monitoreo Arqueológico, INPC, Quito.

Di Pasquale, G. et al. 2008, "The Holocene Treeline in the Northern Andes (Ecuador): First Evidence from Soil Charcoal”, en: Palaeogeography, Palaeoclimatology, Palaeoecology, 259, pp. 17-34.

Domínguez, V. 2009, Prospección Intra-sitio, Excavación y Monitoreo en el Área Ciudad Bicentenario - Sitio Arqueológico Tajamar Z3B1-017 (lado sur), IMP, Quito.

Dyrdahl, E. 2017, Informe de Adquisición de Obsidiana del Sitio Nona-Sadiguena, usando Flourescencia de Rayos X Portatil (PXRF), Quito.

Echeverría, J. 1996, Informe de la Observación de Asentamientos Antiguos en Oyacachi-El Chaco (Provincia de Napo), Canelos-Chapetón (Provincia de Pastaza), Macuma-Muntins y Área de San Luis de Inikes (Provincia de Morona Santiago), Región Amazónica Ecuatoriana, DIVA-INPC, Quito.

Echeverría, J., \& Berenger, J. 1995, “Excavaciones en Tababuela, Imbabura, Ecuador”, en: Echeverría, J. \& M. Uribe, Área Septentrional Andina Norte: Arqueología y Etnohistoria, Abya Yala, Quito, pp.149-252.

Jara, H., \& Santamaría, A. 2009, Atlas Arqueológico del Distrito Metropolitano de Quito - Pintag, FONSAL, Quito.

Marcos, J. et al. 2002, "El Tráfico a Distancia Temprano entre la Hoya de Quito y la Península de Santa Elena, las Evidencias de Real Alto", en: Cardenas, F. et al., Intercambio y Comercio en los Andes: La Interacción Tierras Altas - Tierras Bajas desde una Perspectiva Arqueológica y Etnohistórica, Abya-Yala, Quito.

Molestina, M. 2014, Las Necrópolis Precerámicas del Periodo Tardio, Quito.

Montalvo, C. 2016, Il Sito de Las Orquideas (Imbabura) nell'ambito del Periodo Formativo Tardo (800-400 a.C.) nel Nord del Ecuador. Sequenza Stratigrafica e Cronologia, Universidad La Sapienza, Tesis Doctoral en Arqueologia, Roma.

Montalvo, C., \& Dyrdahl, E. 2014, Informe Final de las Intervenciones Realizadas en el Yacimiento Arqueológico "Las Orquideas", Parroquia de San Antonio, Provincia de Imbabura, INPC, Quito.

Ontandea, S. 2010, Historia de los Pueblos Precolombinos de la Sierra Norte del Ecuador, Banco Central del Ecuador, Quito.

Pazmiño, E. 2016, Pottery Production and Social Complexity in the Valle de Quijos. Alberta, University of Lethbridge, Tesis de Maestría, Canada.

Porras, P. 1975, Fase Cosanga, Centro de Publicaciones PUCE, Quito.

Ribeiro, D. 1970, Os Índios e a Civilizacao; a Integracao das Populacoes Indígenas no Brasil Moderno, Schwarcz LTDA, San Pablo.

Romero Bastidas, M. 2011, “Análisis por Difracción de Rayos X de cerámicas de los sitios arqueológicos Rumipamba”, en: INPC, Las Técnicas Analiticas Nucleares y el Patrimonio, Ediecuatorial, Quito, pp.73-86. 
Romero, M. 2010, Informe de Análisis Especializados de Muestras Recuperadas en la Necrópolis de la Unidad 95 del NAIQ, INPC, Quito.

Salazar, E. 1992, "El intercambio de Obsidiana en el Ecuador Precolombino: Perspectivas Teórico - Metodológicas”, en: Politis, G. Arqueología en América Latina Hoy, Fondo de Promoción de la Cultura, Banco Popular, Buenos Aires, pp.117-131.

Salomon, F. 2011, Los Señores Étnicos de Quito en la Época de los Incas: La Economía Política de los Señoríos Norandinos, IMP, Quito.

Sánchez, A. \& Merino, Y. 2013, Formas Cerámicas en Contextos Regionales del Neotrópico Ecuatoriano. Guayaquil, Quadrivium, Ecuador.

Serrano, S. 2017, Etnoarqueología de Intercambio y de Bienes y Productos en los Caminos Precolombinos de Pichincha y Napo, Guayaquil: ESPOL, Tesis de Maestría, Ecuador.

2016 , "La Industria Lítica de Palmira", en: Chacón R., Informe Final Monitoreo y Rescate Arqueológico en el Proyecto Palmira, Nanegal, HIDROEQUINOCCIO-INPC, Quito.

Torres, P. 2014, Prácticas Funerarias y Demografia en el Periodo Formativo Temprano del Valle de Quito, Perspectivas en el Estudio de Interacciones entre Grupos y Complejidad Social, Pontificia Universidad Católica del Ecuador, Facultad de Ciencias Humanas, Quito.

Ugalde, M. 2014, Contrato Complementario Rancho Bajo, Provincia de Pichincha, IMP-INPC, Quito.

Valverde, V. 2016, Informe Petrográfico de Cenizas del Sitio Arqueológico Nona-Sadiguena, Instituto Geofísico de la EPN, Quito.

Van der Hammen, T. et al. 2003, “Un Diagrama de Polen del Pleistoceno Final y Holoceno de Mullumica”, en: Maguaré, 17 , pp. 247-259.

Villalba, M. 2005, Mapa Arqueológico de Distrito Metropolitano, Prospección Arqueológica Pintag, Bloque SE, Primera Etapa. Tomo I, Análisis de Materiales, FONSAL-INPC, Quito.

1988, Cotocollao: Una Aldea Formativa del Valle de Quito. Banco Central del Ecuador, Quito

Villota, A. et al. 2014, "Mid- and Late Holocene Vegetation and Environmental Dynamics in the Llanganates National Park, Anteojos Valley, Central Ecuadorian Andes”, en: Palynology Journal, pp. 94-122. 